\title{
Evaluation of reproductive toxicity in rats treated with triclosan
}

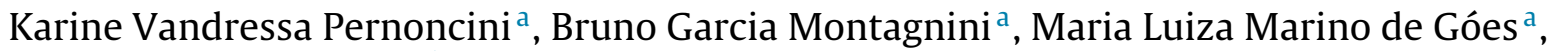 \\ Patricia Carvalho Garcia ${ }^{\mathrm{b}}$, Daniela Cristina Ceccatto Gerardin ${ }^{\mathrm{a}, *}$ \\ a Department of Physiological Sciences, Center of Biological Sciences, State University of Londrina - UEL, Londrina, PR, Brazil \\ ${ }^{\mathrm{b}}$ Department of Medical Clinics, Botucatu Medical School, São Paulo State University "Júlio de Mesquita Filho" - UNESP, Botucatu, SP, Brazil
}

\section{A R T I C L E I N F O}

\section{Article history:}

Received 1 June 2017

Received in revised form 1 November 2017

Accepted 28 November 2017

Available online 29 November 2017

\section{Keywords:}

Antibacterial

Sperm parameters

Sexual behaviour

Environmental contaminant

Endocrine disruptor

\begin{abstract}
A B S T R A C T
Triclosan (TCS) is an antibacterial agent used in a variety of consumer products such as: soaps, deodorant, and toothpaste, among others. Some studies have reported the (anti)androgenic effects of TCS in the male reproductive system, raising concerns about its effects on the reproductive axis. In this study, the (anti)androgenicity of TCS was evaluated in the Hershberger assay in 52-day old male Wistar rats. Additionally, the sexual behavior, sperm motility, sperm viability, and testicular histomorphometry were evaluated in a second protocol to investigate the reproductive effects of TCS in 49-day old male Wistar rats. The dosages were administered based on the acceptable daily intake for TCS, in addition to 3 and 10-fold higher doses. Our results demonstrated that TCS, in the doses administered, did not act as an endocrine disrupter (ED), with no (anti)androgenic effect in the Hershberger assay and without interfering with the parameters evaluated in the reproductive toxicity study.
\end{abstract}

(C) 2017 Elsevier Inc. All rights reserved.

\section{Introduction}

Interest in monitoring environmental contaminants (such as pesticides, heavy metals, therapeutic drugs, phenolic derivatives, and/or other persistent xenobiotics) is mainly due to recognition of their negative effects relative to environmental endocrine disruption in wildlife and human health [1]. Endocrine disrupters (EDs) are environmental contaminants described by the International Programme on Chemical Safety as an exogenous substance or mixture that alters function(s) of the endocrine system with adverse health effects in an intact organism, its progeny, or (sub)populations [2]. In human populations, exposure to EDs points towards an association with reproductive disorders, such as early puberty $[3,4]$, poor sperm quality and/or function [5,6], and prostate cancer [7].

Triclosan (TCS) (2,4,4'-trichloro-2'-hydroxydiphenyl ether) is a phenolic compound with antibacterial properties applied to a variety of consumer products, such as personal care products (cos-

Abbreviations: EDs, endocrine disrupters; TCS, triclosan; CTR, control; PND, postnatal day; TP, testosterone propionate; EPA, Environmental Protection Agency; LABC, levator ani bulbocavernosus; DSP, daily sperm production; LST, total length of the seminiferous tubules; TSV, tubule seminiferous volume; $\pi \mathrm{R} 2$, area of transverse section of seminiferous tubules.

* Corresponding author at: Department of Physiological Sciences, State University of Londrina- UEL, Londrina, Paraná, 86051-980, Brazil.

E-mail address: dcgerardin@uel.br (D.C.C. Gerardin). metics, toothpaste, shampoo, hand soaps, deodorants, and body oils), textiles, and toys, among others [8-10]. Due to its widespread use over the past decades, TCS has become one of the most commonly detected contaminants in solid and water environmental compartments [11,12]. In rivers in the state of São Paulo (Brazil), the measurable concentrations of TCS in surface waters ranged from 2.2 to $66 \mathrm{ng} / \mathrm{L}$ [13], and as TCS is only partially removed in wastewater treatment plants [12], this compound has also been found in drinking water [14].

In humans, the major routes of exposure to TCS occur through topical absorption and the gastrointestinal tract [15-17], in addition, it has been demonstrated that frequent contact with TCS is associated with higher concentrations of this compound in the urine of individuals $\geq 6$ years of age [18], in breast milk [19], and in human umbilical cord blood plasma [20]. Some experimental evidence has demonstrated the potential for TCS to act as an ED in the reproductive system. In Sprague-Dawley rats, TCS showed a tendency to accumulate in the epididymis after a single oral administration $(50 \mathrm{mg} / \mathrm{kg})$, and after 8 weeks of treatment starting on post-natal day (PND) 42, decreased daily sperm production was observed at doses of 50 and $200 \mathrm{mg} / \mathrm{kg}$ [21]. Moreover, the oral treatment $(200 \mathrm{mg} / \mathrm{kg})$ for 31 days decreased serum testosterone in immature male Wistar rats (23 days old) [22], and in 10 week old rats, there was a decrease in the synthesis of androgens followed by reduced daily sperm production, after 60 days of oral administrations (20 mg/kg) [23]. In vitro, TSC demonstrated antiandrogenic action by disrupting the activity of the adenylyl cyclase 
enzyme, decreasing biosynthesis of testosterone in rodent Leydig cells [24], and inhibiting transcriptional activation by testosterone in human embryonic kidney cells [25], while exhibiting androgenic activity by displacing testosterone of the androgen receptor binding domain in androgen-responsive breast cancer cells [26].

Therefore, considering the extensive use of TCS, its occurrence in the environment, its endocrine-disrupting potential in the male reproductive system and given the few data available in the literature regarding the reproductive toxicity of TCS, this study aimed to detect possible (anti)androgenic effects of TCS using the Hershberger assay, in addition to evaluating the sexual behavior, sperm motility, sperm viability, and testicular histomorphometry in a reproductive toxicity study.

\section{Material and methods}

\subsection{Drugs}

TCS was obtained from Vivimed Labs Limited (Habsiguda Hyderabad, India) (CAS no. 3380-34-5, 99.38\% pure), and testosterone propionate (TP) (CAS no. 57-85-2, 99.41\% pure) and flutamide (CAS no. 13311-84-7, 99.60\% pure) were obtained from Fragon (São Paulo, Brazil). Except for TP, which was administered subcutaneously, all chemicals were dissolved in corn oil (vehicle) and administered orally, by gavage, in a volume of $2.5 \mathrm{ml} / \mathrm{kg}$.

\subsection{Animals}

Male and female Wistar rats were obtained from the colony of the State University of Londrina and maintained in a controlled environment with a temperature of $21 \pm 2{ }^{\circ} \mathrm{C}$; a $12 \mathrm{~h}$ light/dark cycle (lights on at 6:00 AM); and free access to regular lab chow (Nuvilab $^{\mathrm{TM}}$, Quimtia SA, Brazil) and tap water. Animals were housed in collective polypropylene cages $(29 \times 18 \times 13 \mathrm{~cm})$ with wood shavings as bedding, and were mated after 1 week of acclimatization. Litters with 8-10 pups were used and, if litters had more than 10 pups, culling was conducted. The day of birth was considered postnatal day (PND) 0 and male pups were weaned on PND 21. After weaning, male pups were distributed for the Hershberger assay or assessment after puberty. No littermates were used in the same experimental group. All animal procedures were approved by the State University of Londrina Ethics Committee for Animal Research (CEUA/UEL: 283.2015.27) and were elaborated and developed based on the principle of the three R's (Refine, Reduce, and Redesign).

\subsection{Hershberger assay}

The study design followed the guideline OPPTS 890.1400 from the U. S. Environmental Protection Agency (EPA) [27]. On PND 42, the rats were anesthetized with sodium pentobarbital $(40 \mathrm{mg} / \mathrm{kg}$, ip) and castrated by making an incision in the scrotum and removing both testes and epididymis with ligation of blood vessels and seminal ducts. On PND 52, the rats were randomly assigned to the experimental groups. Weight variation among the animals on the first day of treatment was $10 \%$.

In order to evaluate the possible androgenicity of TCS, the rats were distributed into the following groups ( $n=6 /$ group):

- CTR (vehicle): rats were treated with corn oil (solvent of TCS);

- TP: rats were treated with $0.4 \mathrm{mg} / \mathrm{kg}$ of TP;

- TCS 0.8: rats were treated with $0.8 \mathrm{mg} / \mathrm{kg}$ of TCS;

- TCS 2.4: rats were treated with $2.4 \mathrm{mg} / \mathrm{kg}$ of TCS;

- TCS 8.0: rats were treated with $8.0 \mathrm{mg} / \mathrm{kg}$ of TCS;

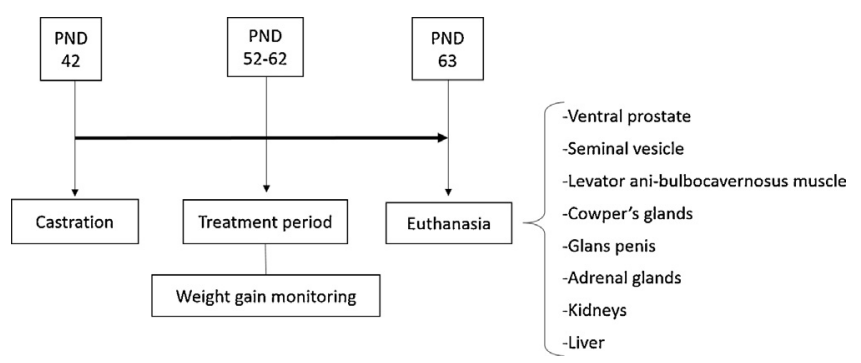

Fig. 1. Diagram of Hershberger assay design. PND: postnatal day.

For evaluation of the possible antiandrogenicity of TSC, the rats were distributed into the following groups ( $n=6 /$ group):

- TP: rats were treated with $0.4 \mathrm{mg} / \mathrm{kg}$ of TP.

- TP + flutamide: rats were treated with $0.4 \mathrm{mg} / \mathrm{kg}$ of TP in addition to $3 \mathrm{mg} / \mathrm{kg}$ of flutamide.

- TCS 0.8 + TP: rats were treated with $0.8 \mathrm{mg} / \mathrm{kg}$ of TCS in addition to $0.4 \mathrm{mg} / \mathrm{kg}$ of TP.

- TCS $2.4+$ TP: rats were treated with $2.4 \mathrm{mg} / \mathrm{kg}$ of TCS in addition to $0.4 \mathrm{mg} / \mathrm{kg}$ of TP.

- TCS 8.0 + TP: rats were treated with $8.0 \mathrm{mg} / \mathrm{kg}$ of TSC in addition to $0.4 \mathrm{mg} / \mathrm{kg}$ of TP.

All chemicals were administered for 10 consecutive days after a 3-h food restriction. Twenty-four hours after the final dose (i.e., PND 62 ), the animals were weighed and euthanized by decapitation. The ventral prostate, seminal vesicle (plus fluids and coagulating glands), levator ani-bulbocavernosus (LABC) muscles, paired Cowper's glands, glans penis, liver, paired kidneys and paired adrenals were removed, trimmed free of fat and weighed. In addition, during the 10-day treatment period, animals were observed daily for mortality, morbidity, and general signs of toxicity, such as changes in behavior (e.g., agitation, lethargy, and hyperactivity), neurological changes (e.g., convulsions, tremors, muscle rigidity, and hyperreflexia), and autonomic signs (e.g., lacrimation, piloerection, pupil size, and unusual respiratory patterns). The experimental protocol is diagrammed in Fig. 1.

\subsection{Reproductive toxicity study}

The study treatment period was undertaken following the principles of the OECD Guideline for Testing of Chemicals 416 [28] designed to provide general information concerning the effects of a xenobiotic on the reproductive system. On PND 49, the male rats were randomly distributed into four groups ( $n=10 /$ group):

- CTR (control): rats were treated with corn oil;

- TCS 0.8: rats were treated with $0.8 \mathrm{mg} / \mathrm{kg}$ of TCS;

- TCS 2.4: rats were treated with $2.4 \mathrm{mg} / \mathrm{kg}$ of TCS;

- TCS 8.0: rats were treated with $8.0 \mathrm{mg} / \mathrm{kg}$ of TCS.

The treatment was performed by gavage once a day, always following the same administration schedule routine (11:00 a.m.-1:00 p.m.) and was conducted until PND 140.

\subsubsection{Dose justification}

According to the U. S. EPA [29], the acceptable daily intake of TCS is up to $0.3 \mathrm{mg} / \mathrm{kg}$, for humans. This value was corrected discounting the allocation factor adopted for TCS exposure in drinking water $[30,31]$, which corresponds to $20 \%$ (i.e., 0.2 ) of the acceptable daily intake value. Subsequently, an approximate value of $0.2 \mathrm{mg} / \mathrm{kg}$ was generated, which was applied to the $\mathrm{BW}^{3 / 4}$ scale [32] for dosimetric adjustment, where the weight of a human of $70 \mathrm{~kg}$ was consid- 


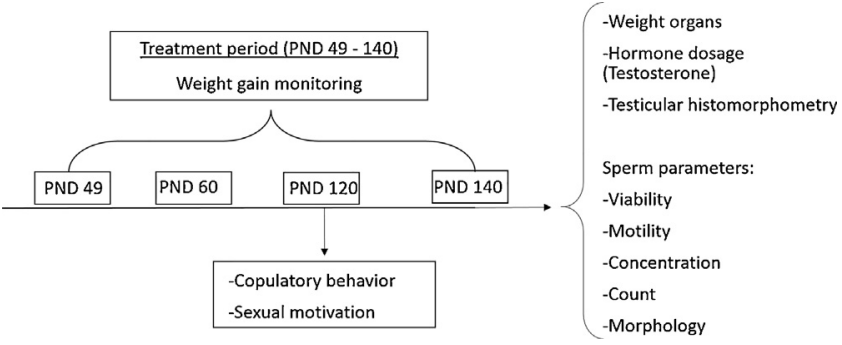

Fig. 2. Diagram of reproductive toxicity study design. PND: postnatal day.

ered and of a rodent of $250 \mathrm{~g}$ to obtain the value of $0.8 \mathrm{mg} / \mathrm{kg}$ as an acceptable daily intake value for rats, which is below the estimated TCS exposure in humans (about $0.13 \mathrm{mg} / \mathrm{kg} /$ day) [33]. The dose of $2.4 \mathrm{mg} / \mathrm{kg}$ was adopted as an intermediate dose and the dose of $8.0 \mathrm{mg} / \mathrm{kg}$ as the factor 10 , assuming intra-species variations. The experimental protocol is diagrammed in Fig. 2.

\subsubsection{Body weight}

The determination of body weight was performed every three days during the treatment period, for analysis of body weight gain and volumetric correction of the doses administered. In addition, signs of toxicity (lacrimation, piloerection, unusual respiratory pattern, and tremors) were observed daily.

\subsubsection{Sexual behavior evaluation}

All behavioral assessments were performed in adult rats (beginning on PND 120) during the dark phase of a reversed light/dark cycle, under dim red light. The animals were allowed a 15day period of adaptation to the reversed light/dark cycle before the beginning of evaluations. The observations always started two/three hours after the onset of darkness and were recorded by a video camera, linked to a monitor in an adjacent room.

2.4.3.1. Copulatory behavior. For the copulatory behavior evaluation, each male was placed into a Plexiglass cage with dimensions of $20 \times 40 \times 50 \mathrm{~cm}$ (height $\times$ width $\times$ length) and, after $5 \mathrm{~min}$, a female in natural estrous was introduced into the cage. For $30 \mathrm{~min}$, the latencies and numbers of intromissions and ejaculations were observed as described previously [34]. If a male did not mount within $10 \mathrm{~min}$, the evaluation was interrupted and repeated another day with another female. If the male failed again in the second evaluation, it was considered sexually inactive [35].

2.4.3.2. Sexual incentive motivation. The same animals evaluated for copulatory behavior were submitted to the sexual incentive motivation test. In this test, a rectangular arena, $50 \times 50 \times 100 \mathrm{~cm}$ (height $\times$ width $\times$ length), was used containing two openings that communicated with two small arenas of $25 \mathrm{~cm}^{2}$. The small arenas were diagonally opposed to each other and the communication with the main arena was closed with wire mesh. For the test, an estrous female (sexual incentive) was placed in one of the small arenas and a sexually active male (social incentive) was placed in the other. The floor of the main arena had two $25 \mathrm{~cm}^{2}$ divisions (zones) in front of each small arena opening, named sexual incentive and social incentive zones, respectively. The experimental male was placed in the center of the main arena and observed for $20 \mathrm{~min}$. The number of visits and total time spent visiting each zone were quantified, and a preference score was calculated as (time spent in female zone/total time spent in both incentive zones $) \times 100$ [36].

\subsubsection{Collection of organs}

Male rats were euthanized by decapitation twenty days after mating (to replace the spermatic stock). The testis (pair), vas def- erens (left), epididymis (left), ventral prostate, liver, kidneys (pair), adrenal glands, and seminal vesicle (pair) (without the coagulating gland and full of secretion) were removed and their weights determined. The right testis and epididymis were frozen at $-80^{\circ} \mathrm{C}$ for sperm counting and the left testis was collected for histomorphometric analysis. The right vas deferens was used for analysis of motility, viability, and sperm concentration and the left for sperm morphology.

\subsubsection{Plasma testosterone quantification}

Blood samples were collected from the abdominal aorta into syringes containing heparin, centrifuged $(2500 \mathrm{rpm}$ for $20 \mathrm{~min}$ at $4{ }^{\circ} \mathrm{C}$ ), and the plasma was frozen until assayed. Plasma testosterone quantification was measured by chemiluminescence microparticle immunoassay (ARCHITECT ${ }^{\circledR}$ 2nd Generation Testosterone) according to the manufacturer's instructions, with an intra-assay coefficient of variation and minimum sensitivity of the assay of $4.6 \%$ and $0.15 \mathrm{nmol} / \mathrm{L}$ respectively.

\subsubsection{Sperm parameters}

2.4.6.1. Sperm motility, viability, concentration and morphology. Sperm was obtained from the right vas deferens and diluted in $1 \mathrm{ml}$ of GV HEPES medium (Ingamed, Brazil) pre-warmed to $34^{\circ} \mathrm{C}$. For sperm motility, a $10 \mu \mathrm{l}$ aliquot was placed in a Makler chamber (Sefi-Medical, Haifa, Israel) and analyzed under a phase-contrast microscope (OSM-223287, Olympus) at $100 \times$ magnification. One hundred spermatozoa were evaluated per animal and classified as motile or immotile $[37,38]$.

For sperm viability, the one step eosin-nigrosin staining technique was used [39]; $50 \mu$ l of spermatozoa in GV HEPES medium (Ingamed, Maringá, Brazil) was mixed with eosin-nigrosin and directly examined, and 100 spermatozoa per animal were evaluated and classified as viable or non-viable.

Sperm concentration $\left(10^{6} / \mathrm{ml}\right)$ analysis was performed in the Makler chamber (Sefi-Medical, Haifa, Israel) [40]. Sperm was counted in 10 different squares chosen at random, in four different fields, and the average was obtained.

The evaluation of sperm morphology was performed according to Fernandes et al. [41]. Sperm were recovered from the left vas deferens by flushing with $1 \mathrm{ml}$ of formol-saline (10\%) and smears were prepared on histological slides that were left to dry for $90 \mathrm{~min}$. In total, 200 spermatozoa were analyzed per animal in a phase-contrast microscope $(400 \times$ magnification $)$ [42]. Morphological abnormalities were classified into two general categories: head morphology (without characteristic curvature or isolated form, i.e., no tail attached) and tail morphology (broken or isolated i.e., no head attached) [43].

2.4.6.2. Daily sperm production per testis, sperm number and transit time in the epididymis. The left testis was decapsulated and the caput/corpus and cauda segments from the epididymis were separated. Homogenization-resistant testicular spermatids (stage 19 of spermiogenesis) and sperm in the caput/corpus epididymis and cauda epididymis were assessed as previously described by Robb et al. [44] with adaptations of Fernandes et al. [41]. Mature spermatids were counted in a Neubauer chamber. To calculate daily sperm production (DSP), the number of spermatids at stage 19 was divided by 6.1 , which is the number of days in one seminiferous cycle when these spermatids are present in the seminiferous epithelium. Sperm transit time through the epididymis was determined by dividing the number of sperm in each segment by the DSP.

\subsubsection{Testicular histomorphometry}

The right testis of rats with PND 140 was promptly dissected, weighed and fixed by immersion in Bouin's solution for 
Table 1

Evaluation of TCS for androgenicity in the Hershberger assay. Body weight and absolute accessory sex organ weight.

\begin{tabular}{|c|c|c|c|c|c|}
\hline & CTR [6] & $\mathrm{TP}[6]$ & TCS $0.8[6]$ & TCS 2.4 [6] & TCS $8.0[6]$ \\
\hline Initial body weight (g) & $204.38 \pm 11.78$ & $194.71 \pm 7.19$ & $206.64 \pm 9.04$ & $208.10 \pm 4.15$ & $208.52 \pm 8.74$ \\
\hline Final body weight (g) & $250.70 \pm 9.39$ & $261.07 \pm 9.72$ & $253.35 \pm 8.72$ & $258.61 \pm 3.89$ & $256.49 \pm 9.19$ \\
\hline Seminal vesicles (mg) & $27.00 \pm 4.40$ & $341.73 \pm 27.49^{*}$ & $24.30 \pm 3.41$ & $23.65 \pm 1.99$ & $32.18 \pm 2.96$ \\
\hline Prostate $(\mathrm{mg})$ & $6.97 \pm 1.03$ & $96.42 \pm 4.03^{*}$ & $4.93 \pm 0.79$ & $6.25 \pm 1.68$ & $8.38 \pm 2.33$ \\
\hline Cowper's glands (mg) & $3.70 \pm 0.53$ & $27.15 \pm 2.54^{*}$ & $2.90 \pm 0.56$ & $4.12 \pm 0.77$ & $4.62 \pm 0.84$ \\
\hline LABC muscle (mg) & $119.83 \pm 7.81$ & $362.38 \pm 21.88^{*}$ & $107.22 \pm 3.53$ & $126.82 \pm 4.84$ & $120.38 \pm 8.83$ \\
\hline Glans penis (mg) & $17.17 \pm 2.14$ & $63.00 \pm 4.48^{*}$ & $16.48 \pm 1.06$ & $16.97 \pm 1.95$ & $17.92 \pm 1.39$ \\
\hline Adrenals (mg) & $53.53 \pm 3.95$ & $43.68 \pm 2.56$ & $53.32 \pm 2.65$ & $57.62 \pm 3.87$ & $50.67 \pm 3.92$ \\
\hline Liver (g) & $10.29 \pm 0.43$ & $12.10 \pm 0.50$ & $9.97 \pm 0.52$ & $10.85 \pm 0.21$ & $11.49 \pm 0.54$ \\
\hline Kidneys (g) & $1.72 \pm 0.10$ & $1.87 \pm 0.07$ & $1.73 \pm 0.07$ & $1.74 \pm 0.06$ & $1.77 \pm 0.07$ \\
\hline
\end{tabular}

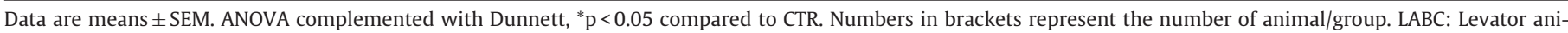

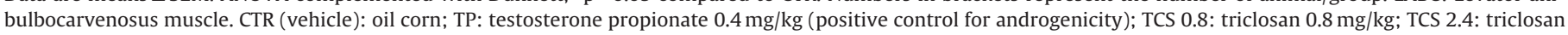
$2.4 \mathrm{mg} / \mathrm{kg}$; TCS 8.0: triclosan $8.0 \mathrm{mg} / \mathrm{kg}$.

$24 \mathrm{~h}$ before being stored in ethanol at $70 \%$. The testis was cut into tissue fragments and routinely processed for embedding in Paraplast. Blocks were sectioned at $7 \mu \mathrm{m}$ and stained with hematoxylin-eosin. The diameter of the seminiferous tubules was measured at $100 \times$ magnification using an ocular micrometer. Fifteen cross sections of tubule profiles that were either round or nearly round were chosen randomly and measured for each animal. The volume densities of testicular tissue components were determined by light microscopy using a 100-intersection grid placed in the ocular of the light microscope. A total of 10 (1000 points) randomly chosen fields were scored for each animal at $400 \times$ magnification. The volume of each component of the testis was determined as the product of the volume density and testis volume. For subsequent stereological calculations, the specific gravity of testis tissue was considered to be 1.0 [45]. To obtain a more precise measure of testis volume, the testis capsule ( $6.5 \%)$ was excluded from the testis weight. The total length (in meters) of seminiferous tubules (LST) was estimated by the tubule seminiferous volume (TSV) in the testis and the average area of tubules obtained from each animal ( $\pi \mathrm{R} 2$; $\mathrm{R}=$ tubular diameter $/ 2$, according to the formula: $\mathrm{LST}=\mathrm{TSV} / \pi \mathrm{R} 2)[46,47]$.

\subsection{Statistical analysis}

An exploratory analysis was conducted to evaluate the normal distribution (Shapiro-Wilk test) and homogeneity of variance (Levene's test) of each variable. Variables that presented normal distribution and homogeneity of variance were analyzed by ANOVA complemented with the Bonferroni or Tukey post-hoc test, with data being presented as mean \pm standard error of the mean (SEM). Conversely, for other variables (latency to the first ejaculation, latency of the first post-ejaculatory intromission, no. of postejaculatory intromissions, plasma testosterone quantification, and total length of seminiferous tubules, viable and non-viable spermatozoa) the Kruskal-Wallis H complemented with Dunn's test were performed with the presentation of data as median (1st and 3rd quartiles). In the Hershberger assay, the weight of the androgendependent tissues were analyzed by ANOVA complemented with 1-tailed Dunnett as suggested in the guideline from U. S. EPA [27]. Moreover, the Coefficient of Variation (CV) presented in the present study, for the target sex accessory tissues, met the criteria from the OECD validation studies [48]. Analysis of covariance (ANCOVA) was used to detect the effect of the treatment on organ weight using the final body weight as the covariate. However, since the ANCOVA and ANOVA provided similar results, the ANOVA results are reported. The Chi-Square test was used to examine differences in categorical variables. Differences were considered significant if $\mathrm{p}<0.05$.

\section{Results}

\subsection{Hershberger assay}

As shown in Table 1, in the study designed to evaluate the possible androgenicity of TCS, ANOVA complemented with the Dunnett's test indicated that TP treatment significantly increased the weight of the androgen-dependent tissues, compared to rats that received the vehicle $(\mathrm{p}<0.05)$. No statistical differences were observed in the weight of the organs of the TSC-treated groups compared to the vehicle group (ANOVA, $\mathrm{p}>0.05$ ).

In the evaluation of the possible antiandrogenic effect of TCS, the concomitant administration of TP with the androgen antagonist flutamide significantly reduced tissue weight gain compared to animals that received only TP $(\mathrm{p}<0.05)$ (Table 2$)$, however, no statistical differences were observed in the TCS-treated groups plus TP (ANOVA, p >0.05).

No mortality, morbidity, or general signs of toxicity such as changes in behavior (e.g., agitation, lethargy, and hyperactivity), neurological changes (e.g., convulsions, tremors, muscle rigidity, and hyperreflexia), or autonomic signs (e.g., lacrimation, piloerection, pupil size, and unusual respiratory patterns) were observed during the treatment period.

\subsection{Male reproductive toxicity}

The sexual behavior evaluation results are shown in Table 3. No statistical difference was detected in the parameters of copulatory or sexual incentive motivation parameters $(p>0.05)$. There were no significant differences between the percentage of animals that displayed copulatory behavior or the frequencies of ejaculations of the TCS-treated groups compared to the CTR group (Chi-Square test, $\mathrm{p}<0.05$ ) (data not shown).

As indicated by ANOVA, body weight gain (g) (PND 140-49) was not influenced by TCS treatment (CTR: 237.71 \pm 11.08 ; TCS 0.8 : $215.78 \pm 13.26$; TCS 2.4: $234.47 \pm 11.75$; TCS 8.0: $224.93 \pm 10.30$ $\mathrm{n}=10 /$ group) $\left[\mathrm{F}_{(3,36)}=0.723, \mathrm{p}=0.545\right]$.

The final body weight $(\mathrm{g})$, organ weights, and plasma testosterone quantification of adult males are presented in Table 4. No significant differences as a result of the TCS treatment were found in final body weight (PND 140) $\left[\mathrm{F}_{(3,36)}=0.202, \mathrm{p}=0.895\right]$, organ weights (ANCOVA, $\mathrm{p}>0.05$ ), or plasma testosterone quantification (ng/dL), $\chi 2(3)=0.678, p=0.878$ (Kruskal-Wallis $\mathrm{H}$ test, $\mathrm{p}>0.05$ ).

No statistical difference was observed in sperm morphology, viability, motility or concentration (Table 5), or in the sperm count (Table 6) ( $\mathrm{p}>0.05)$.

The testicular histomorphometry is presented in Table 7 . No changes in testicular volume $\left[\mathrm{F}_{(3,35)}=0.110, \mathrm{p}=0.954\right]$, interstitial content volume $\left[\mathrm{F}_{(3,35)}=0.317, \mathrm{p}=0.813\right]$, seminiferous tubules volume $\left[F_{(3,35)}=0.088, p=0.966\right]$, or the diameter of seminifer- 
Table 2

Evaluation of TCS for antiandrogenicity in the Hershberger assay. Body weight and absolute accessory sex organ weight.

\begin{tabular}{|c|c|c|c|c|c|}
\hline & $\mathrm{TP}[6]$ & TP + FLUT [6] & TP + TCS $0.8[6]$ & $\mathrm{TP}+\mathrm{TCS} 2.4[6]$ & TP+ TCS $8.0[6]$ \\
\hline Initial body weight ( $\mathrm{g}$ ) & $194.71 \pm 7.19$ & $211.21 \pm 10.11$ & $203.94 \pm 13.30$ & $209.24 \pm 5.99$ & $207.43 \pm 8.64$ \\
\hline Final body weight $(\mathrm{g})$ & $261.07 \pm 9.72$ & $266.03 \pm 9.43$ & $264.59 \pm 15.59$ & $269.05 \pm 9.48$ & $268.31 \pm 11.63$ \\
\hline Seminal vesicles (mg) & $341.73 \pm 27.49$ & $112.35 \pm 14.05^{*}$ & $374.38 \pm 45.62$ & $412.78 \pm 49.32$ & $381.53 \pm 38.20$ \\
\hline Prostate (mg) & $96.42 \pm 4.03$ & $40.77 \pm 5.61^{*}$ & $110.28 \pm 10.64$ & $98.90 \pm 13.23$ & $90.08 \pm 13.53$ \\
\hline Cowper's glands (mg) & $27.15 \pm 2.54$ & $15.40 \pm 1.46^{*}$ & $27.83 \pm 3.49$ & $31.33 \pm 2.89$ & $27.78 \pm 2.62$ \\
\hline LABC muscle (mg) & $362.38 \pm 21.88$ & $224.23 \pm 7.79^{*}$ & $347.12 \pm 32.70$ & $374.95 \pm 12.92$ & $365.00 \pm 26.12$ \\
\hline Glans penis (mg) & $63.00 \pm 4.48$ & $35.45 \pm 3.06^{*}$ & $59.02 \pm 4.04$ & $61.92 \pm 2.59$ & $57.93 \pm 5.92$ \\
\hline Adrenals (mg) & $43.68 \pm 2.56$ & $48.23 \pm 1.85$ & $47.10 \pm 3.81$ & $44.97 \pm 2.68$ & $45.30 \pm 2.89$ \\
\hline $\operatorname{Liver}(\mathrm{g})$ & $12.10 \pm 0.50$ & $12.04 \pm 0.70$ & $11.21 \pm 0.90$ & $12.34 \pm 0.70$ & $12.02 \pm 0.59$ \\
\hline Kidneys (g) & $1.87 \pm 0.07$ & $1.89 \pm 0.08$ & $1.68 \pm 0.18$ & $1.80 \pm 0.09$ & $1.87 \pm 0.07$ \\
\hline
\end{tabular}

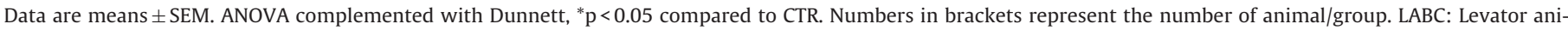

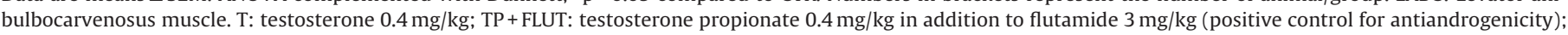

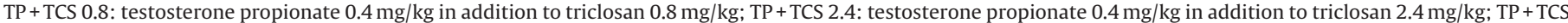
8.0: testosterone propionate $0.4 \mathrm{mg} / \mathrm{kg}$ in addition to triclosan $8.0 \mathrm{mg} / \mathrm{kg}$.

Table 3

Sexual behavior of male rats at PND 120.

\begin{tabular}{|c|c|c|c|c|}
\hline Copulatory behavior & CTR & TCS 0.8 & TCS 2.4 & TCS 8.0 \\
\hline $\begin{array}{l}\text { Latency to the first } \\
\text { intromission (s) }\end{array}$ & $282.90 \pm 74.72\{6 / 10\}$ & $344.40 \pm 98.56\{5 / 10\}$ & $400.10 \pm 65.20\{4 / 10\}$ & $173.90 \pm 37.65\{6 / 10\}$ \\
\hline $\begin{array}{l}\text { Number of } \\
\text { intromissions until the } \\
\text { first ejaculation }\end{array}$ & $21.33 \pm 4.02\{6 / 10\}$ & $14.60 \pm 4.26\{5 / 10\}$ & $17.25 \pm 6.34\{4 / 10\}$ & $17.67 \pm 5.29\{6 / 10\}$ \\
\hline $\begin{array}{l}\text { Latency to the first } \\
\text { ejaculation (s) }\end{array}$ & $\begin{array}{l}853.59(794.92-944.64) \\
\{5 / 6\}\end{array}$ & $\begin{array}{l}963.08(838.90-1208.54) \\
\{4 / 5\}\end{array}$ & $\begin{array}{l}1135.44(913.00-1357.87) \\
\{2 / 4\}\end{array}$ & $\begin{array}{l}877.03(657.36-916.19) \\
\{5 / 6\}\end{array}$ \\
\hline $\begin{array}{l}\text { Latency of the first } \\
\text { post-ejaculatory } \\
\text { intromission (s) }\end{array}$ & $\begin{array}{l}298.89(298.44-316.14) \\
\{5 / 6\}\end{array}$ & $\begin{array}{l}309.18(306.12-314.60) \\
\{4 / 5\}\end{array}$ & $\begin{array}{l}326.44(289.60-363.27) \\
\{2 / 4\}\end{array}$ & $\begin{array}{l}350.80(332.40-375.22) \\
\{5 / 6\}\end{array}$ \\
\hline $\begin{array}{l}\text { Number of } \\
\text { post-ejaculatory } \\
\text { intromissions }\end{array}$ & $13.00(10.00-14.00)\{5 / 6\}$ & $14.00(9.75-17.00)\{4 / 5\}$ & $12.50(10.25-14.75)\{2 / 4\}$ & $16.00(12.00-17.00)\{5 / 6\}$ \\
\hline Number of ejaculations & $2.00 \pm 0.44\{5 / 6\}$ & $1.60 \pm 0.60\{4 / 5\}$ & $1.00 \pm 0.70\{2 / 4\}$ & $1.66 \pm 0.33\{5 / 6\}$ \\
\hline $\begin{array}{l}\text { Sexual incentive } \\
\text { motivation }\end{array}$ & CTR $[10]$ & TCS $0.8[10]$ & TCS $2.4[10]$ & TCS $8.0[10]$ \\
\hline $\begin{array}{l}\text { Time spent in male } \\
\text { zone }(s)\end{array}$ & $406.64 \pm 56.52$ & $424.62 \pm 52.90$ & $339.32 \pm 64.40$ & $431.50 \pm 57.14$ \\
\hline $\begin{array}{l}\text { Time spent in female } \\
\text { zone }(s)\end{array}$ & $462.55 \pm 50.42$ & $442.15 \pm 64.11$ & $584.54 \pm 74.55$ & $479.84 \pm 63.08$ \\
\hline $\begin{array}{l}\text { Number of visits in } \\
\text { male zone }\end{array}$ & $18.00 \pm 1.15$ & $17.20 \pm 1.28$ & $17.00 \pm 1.44$ & $17.10 \pm 0.99$ \\
\hline $\begin{array}{l}\text { Number of visits in } \\
\text { female zone }\end{array}$ & $19.40 \pm 1.39$ & $17.40 \pm 1.51$ & $18.10 \pm 1.33$ & $17.30 \pm 1.30$ \\
\hline Preference Score & $53.65 \pm 5.91$ & $49.98 \pm 6.57$ & $62.63 \pm 7.19$ & $52.33 \pm 6.15$ \\
\hline
\end{tabular}

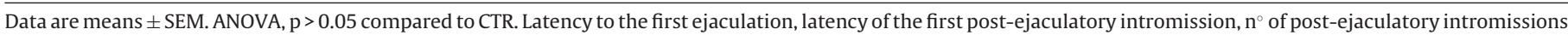

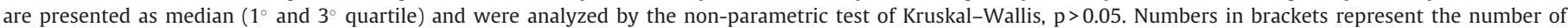
animal/group that displayed the behavior. CTR: corn oil; TCS 0.8: triclosan $0.8 \mathrm{mg} / \mathrm{kg}$; TCS 2.4: triclosan $2.4 \mathrm{mg} / \mathrm{kg}$; TCS 8.0 : triclosan $8.0 \mathrm{mg} / \mathrm{kg}$.

Table 4

Body weight, organ weights, plasma testosterone quantification of male rats at PND 140.

\begin{tabular}{|c|c|c|c|c|}
\hline & CTR [10] & TCS $0.8[10]$ & TCS 2.4 [10] & TCS $8.0[10]$ \\
\hline Final body weight (g) & $421.96 \pm 14.85$ & $405.97 \pm 18.97$ & $420.93 \pm 16.05$ & $416.86 \pm 14.92$ \\
\hline \multicolumn{5}{|l|}{ Organs weight } \\
\hline Tests $(\mathrm{g})$ & $3.26 \pm 0.23$ & $3.24 \pm 0.28$ & $3.19 \pm 0.26$ & $3.22 \pm 0.21$ \\
\hline Vas deferens (left) (mg) & $104.42 \pm 12.07$ & $106.25 \pm 18.68$ & $110.50 \pm 13.38$ & $102.35 \pm 16.79$ \\
\hline Epididymis (left) (mg) & $617.43 \pm 44.77$ & $618.55 \pm 71.19$ & $605.84 \pm 55.03$ & $618.93 \pm 52.45$ \\
\hline Ventral prostate (g) & $0.36 \pm 0.09$ & $0.44 \pm 0.10$ & $0.41 \pm 0.09$ & $0.44 \pm 0.13$ \\
\hline Liver $(\mathrm{g})$ & $13.63 \pm 1.41$ & $12.59 \pm 2.21$ & $14.24 \pm 1.36$ & $13.72 \pm 1.99$ \\
\hline Kidneys (g) & $2.53 \pm 0.27$ & $2.40 \pm 0.30$ & $2.59 \pm 0.25$ & $2.50 \pm 0.33$ \\
\hline Adrenal glands (mg) & $50.65 \pm 8.62$ & $54.20 \pm 10.69$ & $53.83 \pm 16.13$ & $51.51 \pm 11.11$ \\
\hline Seminal vesicle $(\mathrm{g})$ & $1.63 \pm 0.34$ & $1.48 \pm 0.32$ & $1.72 \pm 0.40$ & $1.57 \pm 0.30$ \\
\hline Testosterone (ng/dl) & $206.83(124.93-390.20)$ & $191.73(146.16-302.25)$ & $268.13(210.50-305.58)$ & $260.42(162.09-314.05)$ \\
\hline
\end{tabular}

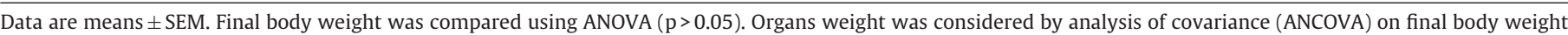

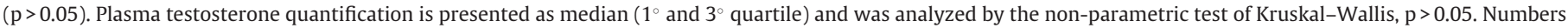
in brackets represent the number of animal/group. CTR: corn oil; TCS 0.8: triclosan $0.8 \mathrm{mg} / \mathrm{kg}$; TCS 2.4: triclosan $2.4 \mathrm{mg} / \mathrm{kg}$; TCS 8.0: triclosan 8.0 mg/kg. 
Table 5

Sperm morphology, viability, motility and concentration of male rats at PND 140.

\begin{tabular}{|c|c|c|c|c|}
\hline Sperm parameters & CTR [10] & TCS $0.8[10]$ & TCS $2.4[10]$ & TCS $8.0[10]$ \\
\hline Abnormal head morphology sperm (\%) & $17.44 \pm 1.96$ & $14.26 \pm 3.41$ & $15.85 \pm 2.03$ & $13.50 \pm 1.01$ \\
\hline Abnormal tail morphology sperm (\%) & $2.16 \pm 0.41$ & $2.73 \pm 0.38$ & $2.14 \pm 0.42$ & $2.78 \pm 0.70$ \\
\hline Concentration of sperm $\left(10^{6} / \mathrm{mL}\right)$ & $39.40 \pm 5.38$ & $44.70 \pm 4.87$ & $40.37 \pm 6.07$ & $41.22 \pm 4.73$ \\
\hline Viable sperm $(\%)$ & $84.50(79.00-87.00)$ & $80.00(75.00-85.75)$ & $84.00(57.25-88.75)$ & $85.00(73.25-88.75)$ \\
\hline Non-viable Sperm (\%) & $15.50(13.00-21.00)$ & $20.00(14.25-25.00)$ & $16.00(11.25-42.75)$ & $15.00(11.25-26.75)$ \\
\hline Mobile sperm (\%) & $77.20 \pm 2.93$ & $77.50 \pm 2.13$ & $73.40 \pm 3.59$ & $79.70 \pm 1.92$ \\
\hline Immobile Sperm (\%) & $22.80 \pm 2.93$ & $22.50 \pm 2.13$ & $26.60 \pm 3.59$ & $20.30 \pm 1.92$ \\
\hline
\end{tabular}

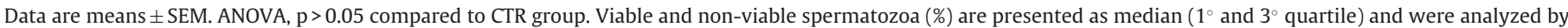

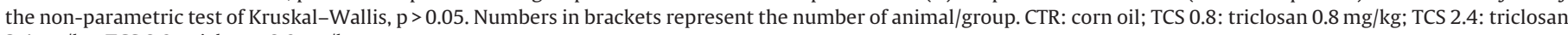
$2.4 \mathrm{mg} / \mathrm{kg}$; TCS 8.0: triclosan $8.0 \mathrm{mg} / \mathrm{kg}$.

Table 6

Sperm count of male rats at PND 140.

\begin{tabular}{|c|c|c|c|c|}
\hline Sperm count & CTR [10] & TCS $0.8[10]$ & TCS $2.4[10]$ & TCS $8.0[10]$ \\
\hline $\mathrm{N}^{\circ}$ of spermatids $\left(10^{6} /\right.$ testis $)$ & $74.64 \pm 8.15$ & $67.00 \pm 1.91$ & $78.26 \pm 6.13$ & $62.58 \pm 5.20$ \\
\hline $\mathrm{N}^{0}$ of spermatids $\left(10^{6} / \mathrm{g} /\right.$ testis $)$ & $52.05 \pm 4.91$ & $46.66 \pm 1.82$ & $54.97 \pm 4.22$ & $43.49 \pm 3.08$ \\
\hline Daily Sperm Production (mg) & $12.24 \pm 1.34$ & $10.98 \pm 3.12$ & $12.83 \pm 1.00$ & $10.26 \pm 8.52$ \\
\hline $\mathrm{N}^{\circ}$ of spermatozoa $\times 10^{6} /$ caput + corpus of epididymis & $59.26 \pm 4.21$ & $56.24 \pm 3.53$ & $61.28 \pm 3.50$ & $56.46 \pm 2.90$ \\
\hline $\mathrm{N}^{\circ}$ of spermatozoa $\times 10^{6} / \mathrm{g} /$ caput + corpus of epididymis & $172.14 \pm 10.93$ & $180.73 \pm 17.86$ & $198.61 \pm 13.36$ & $174.34 \pm 8.45$ \\
\hline $\mathrm{N}^{\circ}$ of spermatozoa $\times 10^{6} /$ cauda of epididymis & $100.44 \pm 7.50$ & $92.74 \pm 6.11$ & $124.20 \pm 7.07$ & $100.31 \pm 9.88$ \\
\hline $\mathrm{N}^{\circ}$ of spermatozoa $\times 10^{6} / \mathrm{g} /$ cauda of epididymis & $357.07 \pm 19.52$ & $322.85 \pm 18.75$ & $397.51 \pm 36.78$ & $343.95 \pm 30.86$ \\
\hline Sperm transit time (days) through caput/corpus of epididymis & $5.18 \pm 0.50$ & $5.12 \pm 0.30$ & $5.14 \pm 0.62$ & $5.85 \pm 0.54$ \\
\hline Sperm transit time through cauda of epididymis (days) & $8.90 \pm 0.94$ & $8.58 \pm 0.71$ & $10.24 \pm 0.95$ & $10.78 \pm 1.63$ \\
\hline
\end{tabular}

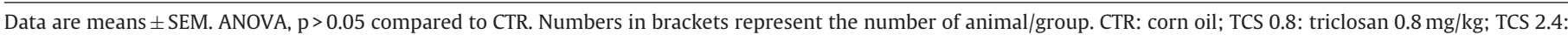
triclosan $2.4 \mathrm{mg} / \mathrm{kg}$; TCS 8.0: triclosan $8.0 \mathrm{mg} / \mathrm{kg}$.

Table 7

Volumetric composition ( $\mathrm{ml}$ ) and biometric evaluation of testicular parenchyma of male rats at PND 140.

\begin{tabular}{|c|c|c|c|c|}
\hline & CTR [10] & TCS $0.8[10]$ & TCS $2.4[10]$ & TCS $8.0[10]$ \\
\hline Testicular volume (ml) & $1.52 \pm 0.03$ & $1.51 \pm 0.04$ & $1.49 \pm 0.04$ & $1.50 \pm 0.03$ \\
\hline Volume of interstitial content (ml) & $0.47 \pm 0.02$ & $0.45 \pm 0.02$ & $0.45 \pm 0.01$ & $0.45 \pm 0.01$ \\
\hline Volume of seminiferous tubules (ml) & $1.04 \pm 0.02$ & $1.05 \pm 0.03$ & $1.03 \pm 0.03$ & $1.05 \pm 0.02$ \\
\hline Diameter of seminiferous tubules $(\mu \mathrm{m})$ & $291.35 \pm 5.20$ & $294.10 \pm 5.63$ & $308.82 \pm 6.30$ & $303.80 \pm 4.74$ \\
\hline Total length of seminiferous tubules ( $\mathrm{m}$ ) & $15.52(14.76-16.65)$ & $16.09(14.88-16.50)$ & $13.54(13.06-13.75)$ & $14.85(14.19-16.03)$ \\
\hline
\end{tabular}

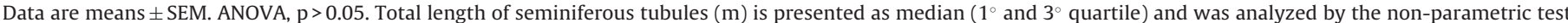

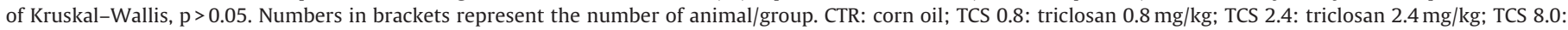
triclosan $8.0 \mathrm{mg} / \mathrm{kg}$.

ous tubules $\left[\mathrm{F}_{(3,35)}=2.202, \mathrm{p}=0.105\right]$ were found. Non-parametric analysis performed by the Kruskal-Wallis $\mathrm{H}$ test did not identify significant changes in the total length of seminiferous tubules, $\chi 2$ (3) $=7.269, p=0.064$, between experimental groups.

No signs of toxicity, such as: lacrimation, piloerection, unusual respiratory pattern, or tremors were observed during the treatment period.

\section{Discussion}

In the present study, the (anti)androgenicity of TCS in male Wistar rats was assessed by the Hershberger assay after 10 consecutive days of oral administration with TCS, and in a second protocol, the male reproductive toxicity of TCS was investigated in post-pubertal rats after 13 weeks of daily oral administration with TCS. The doses used in this work were based on the acceptable daily intake of TCS allowed by the U. S. EPA [29], in addition to 3 and 10 -fold higher doses. All three doses were selected to determine the possible effects of low doses for risk assessment to the male reproductive system and were below the $\mathrm{LD}_{50}(>5000 \mathrm{mg} / \mathrm{kg})$, when administered orally $[29,49]$.

The Hershberger assay is a short-term screening assay designed to identify substances that act as androgen agonists or antagonists and is part of the Endocrine Disruption Screening Program (EDSP) developed by the U. S. EPA [27]. In the Hershberger assay, TCS administration did not increase the weight of the androgen- dependent tissues in the androgenic evaluation, or decrease the weight of the androgen-dependent tissues co-treated with TP in the antiandrogenic evaluation. Although some previously published results from the literature suggest that TCS exhibits antiandrogenic activity in different endogenous androgen-mediated in vitro assays [9,25,26,50], a review by Mihaich et al. [51] does not support the hypothesis that TCS exhibits the potential to interact with components of the androgen pathway. The lack of effects in the Hershberger assay in the present study suggests that TCS does not induce any androgenic/antiandrogenic effects in Wistar rats, at least at the doses used. This result is similar to that reported in the study of Zorrilla et al. [22], where the oral treatment with TCS from PND 23 to $53(3,30,100,200$, and $300 \mathrm{mg} / \mathrm{kg})$ did not affect the weights of androgen-dependent tissues (ventral prostate, seminal vesicles, LABC, epididymal and testes) of pubertal male Wistar rats.

The reproductive toxicity of TCS was also evaluated in 49day-old pubertal male rats after approximately 90 days of oral treatment. The present work was based on the OECD Guideline for Testing of Chemicals 416 [28], and as suggested by the guideline, animals were treated with TCS for 71 days prior to mating, when analysis of sexual behaviors (copulatory behavior and sexual incentive motivation) was conducted (PND 120). In the rodent brain, both testosterone and $17 \mathrm{~b}$-estradiol in the medial preoptic area are needed for the dopamine response and full expression of male sexual behavior [52,53]. Decreased serum testosterone con- 
centrations have already been described in adult Wistar rats (10 weeks old), after 60-day oral administration of TCS, at the dose of $20 \mathrm{mg} / \mathrm{kg}$ [23] and in pre-pubertal Wistar rats, after 31 days of oral treatment with TCS (beginning on PND 23), at the dose of $200 \mathrm{mg} / \mathrm{kg}$ [22]. Despite the potential effects of TCS on testosterone levels, no influence on sexual behavior was observed following the TCS treatments in this analyze. The highest dose used in the present study $(8.0 \mathrm{mg} / \mathrm{kg})$ was, respectively, 2.5 and 25 times lower than the doses used in previous studies (20 and $200 \mathrm{mg} / \mathrm{kg}$ ) [22,23], and may explain the absence of effects on sexual behavior as well as plasma testosterone concentrations at the time of euthanasia.

In toxicity studies, the growth of an animal and the weight of organs are sensitive to the toxic effects of a xenobiotic [54,55]. In the present study, long-term treatment with TCS did not influence body weight gain during the treatment period. This result is consistent with those observed in Wistar rats (around 10 weeks old) orally treated with TCS, for 60 days, at doses of 5,10 , and $20 \mathrm{mg} / \mathrm{kg}$ [23], as well as in pre-pubertal (PND 23) rats, after 31 days of TCS administration, by gavage, at doses of 3, 30, 100, 200, and $300 \mathrm{mg} / \mathrm{kg}$ [22]. In this research, the repeated treatment with TCS also did not affect the organ weights. In the study conducted by Kumar et al. [23], previously discussed, oral treatment with TCS decreased the weight of the testis, but only at the higher doses ( 10 and $20 \mathrm{mg} / \mathrm{kg}$ ), and not at the dose of $5 \mathrm{mg} / \mathrm{kg}$, suggesting that the toxic effects of TCS on hormone dependent organs only appears from oral doses above $10 \mathrm{mg} / \mathrm{kg}$. Considering that the selected reference dose for TCS by dietary exposure in humans is $0.3 \mathrm{mg} / \mathrm{kg} /$ day [29], the absence of effects on body weight and organ weights observed in our study suggests that the environmental exposure levels of protection for TCS incorporated by regulatory frameworks are safe for general toxicity.

Related to sperm parameters, it is known that reduction in sperm quality is commonly linked to the effects of a drug on the spermatogenesis process [56,57], which is totally dependent on the action of testosterone [58]. There are few studies investigating the effects of TCS on sperm quality in rodents. In Sprague Dawley rats (PND 42), oral doses of 50 and $200 \mathrm{mg} / \mathrm{kg}$ decreased daily sperm production and increased the number of abnormal sperm in rats treated with TCS for 8 weeks [21], while in Wistar rats, oral treatment with TCS, for a period of 60 days, reduced the daily sperm production at the dose of $20 \mathrm{mg} / \mathrm{kg}$ [23]. Despite the evidence of spermatic toxicity of TCS in rodents, repeated administrations with TCS did not affect the sperm parameters in this study, suggesting that long-term treatment with TCS, at the tested doses, is not able to impair spermatogenesis related processes in rats. These findings were expected, since plasma testosterone concentrations were unchanged at the time of euthanasia.

The volume of seminiferous tubules has a direct correlation with testicular parameters, such as tubular length, sperm production, and Sertoli cell population [59]. Changes in seminiferous tubules may reflect changes in testes weights [55], an association already reported in Wistar rats, in addition to histopathological malformations [23]. In Kumar et al. [23], daily treatment with TCS at a dosage level of $20 \mathrm{mg} / \mathrm{kg}$ also decreased mRNA levels of proteins associated with steroidogenesis, suggesting a reduction in Leydig cell number. The lack of studies investigating the effects of TCS on the integrity of testicular parenchyma restricts the discussion and reinforces the need for future research. However, based on the histomorphometric results observed in the present study, it can be stated that long-term treatment with TCS did not cause any damage to the integrity of the testicular parenchyma.

In conclusion, the absence of effects of TCS in the Hershberger assay, as well as on the parameters evaluated in the reproductive toxicity study in male rats, reinforce that the exposure limits of TCS imposed by regulatory authorities are safe regarding the TCS endocrine disrupting effects on reproductive function for the general population.

\section{Conflict of interest statement}

The authors declare that there are no conflicts of interest.

\section{Acknowledgments}

This work was supported by CNPq (454499/2014-0) and CAPES (Master fellowship to KVP and Doctoral fellowship to BGM)

\section{References}

[1] T.M. Crisp, E.D. Clegg, R.L. Cooper, W.P. Wood, D.G. Anderson, K.P. Baetcke, J.L. Hoffmann, M.S. Morrow, D.J. Rodier, J.E. Schaeffer, L.W. Touart, M.G. Zeeman, Y.M. Patel, Environ. Health Perspect. 106 (1998) 11-56, http://dx.doi.org/10. 1289/ehp.98106s111 (c. Suppl).

[2] International Program on Chemical Safety (IPCS), Global Assessment of the State-of-the-Science of Endocrine Disruptors, WHO/PCS/EDC/02.2, Geneva, 2002.

[3] M. Krstevska-Konstantinova, C. Charlier, M. Craen, M. Du Caju, C. Heinrichs, C. de Beaufort, G. Plomteux, J.P. Bourguignon, Sexual precocity after immigration from developing countries to Belgium: evidence of previous exposure to organochlorine pesticides, Hum. Reprod. 16 (2001) 1020-1026, http://dx.doi.org/10.1093/humrep/16.5.1020.

[4] F. Deng, F. Tao, D. Liu, Y. Xu, J. Hao, Y. Sun, P. Su, Effects of growth environments and two environmental endocrine disruptors on children with idiopathic precocious puberty, Eur. J. Endocrinol. 166 (2012) 803-809, http:// dx.doi.org/10.1530/EJE-11-0876.

[5] S. Safe, Endocrine disruptors and falling sperm counts: lessons learned or not!, Asian J. Androl. 15 (2013) 191-194, http://dx.doi.org/10.1038/aja.2012.87.

[6] R. Rozati, P. Reddy, P. Reddanna, R. Mujtaba, Role of environmental estrogens in the deterioration of male factor fertility, Fertil. Steril. 78 (2002) 1187-1194, http://dx.doi.org/10.1016/S0015-0282(02)04389-3.

[7] M.C.R. Alavanja, C. Samanic, M. Dosemeci, J. Lubin, R. Tarone, C.F. Lynch, C. Knott, K. Thomas, J.A. Hoppin, J. Barker, J. Coble, D.P. Sandler, A. Blair, Use of agricultural pesticides and prostate cancer risk in the Agricultural Health Study cohort, Am. J. Epidemiol. 157 (2003) 800-814, http://dx.doi.org/10. $1093 /$ aje/kwg040.

[8] A.D. Russell, Whither triclosan? J. Antimicrob. Chemother. 53 (2004) 693-695, http://dx.doi.org/10.1093/jac/dkh171.

[9] K.C. Ahn, B. Zhao, J. Chen, G. Cherednichenko, E. Sanmarti, M.S. Denison, B. Lasley, I.N. Pessah, D. Kültz, D.P.Y. Chang, S.J. Gee, B.D. Hammock, In vitro biologic activities of the antimicrobials triclocarban, its analogs, and triclosan in bioassay screens: receptor-Based bioassay screens, Environ. Health Perspect. 116 (2008) 1203-1210, http://dx.doi.org/10.1289/ehp.11200.

[10] S.S. Ramos, Triclosan, Acta Crystallogr. Sect. C Cryst. Struct. Commun. 65 (2009) 0404-0405, http://dx.doi.org/10.1107/S0108270109026511.

[11] S. Chu, C.D. Metcalfe, Simultaneous determination of triclocarban and triclosan in municipal biosolids by liquid chromatography tandem mass spectrometry, J. Chromatogr. A 1164 (2007) 212-218, http://dx.doi.org/10. 1016/j.chroma.2007.07.024.

[12] G. Bedoux, B. Roig, O. Thomas, V. Dupont, B. Le Bot, Occurrence and toxicity of antimicrobial triclosan and by-products in the environment, Environ. Sci. Pollut. Res. 19 (2012) 1044-1065, http://dx.doi.org/10.1007/s11356-0110632-z.

[13] C.C. Montagner, W.F. Jardim, P.C. Von der Ohe, G.A. Umbuzeiro, Occurrence and potential risk of triclosan in freshwaters of São Paulo, Brazil-the need for regulatory actions, Environ. Sci. Pollut. Res. 21 (2014) 1850-1858, http://dx. doi.org/10.1007/s11356-013-2063-5.

[14] K.C. Machado, M.T. Grassi, C. Vidal, I.C. Pescara, W.F. Jardim, A.N. Fernandes, F.F. Sodré, F.V. Almeida, J.S. Santana, M.C. Canela, C.R.O. Nunes, K.M. Bichinho, F.J.R. Severo, A preliminary nationwide survey of the presence of emerging contaminants in drinking and source waters in Brazil, Sci. Total Environ. 572 (2016) 138-146, http://dx.doi.org/10.1016/j.scitotenv.2016.07.210.

[15] T. Moss, D. Howes, F. Williams, Percutaneous penetration and dermal metabolism of triclosan (2, 4, 4'-trichloro-2'-hydroxydiphenyl ether), Food Chem. Toxicol. 38 (2000) 361-370, http://dx.doi.org/10.1016/S02786915(99)00164-7.

[16] C. Queckenberg, J. Meins, B. Wachall, O. Doroshyenko, D. Tomalik-Scharte, B. Bastian, M. Abdel-Tawab, U. Fuhr, Absorption, pharmacokinetics, and safety of triclosan after dermal administration, Antimicrob. Agents Chemother. 54 (2010) 570-572, http://dx.doi.org/10.1128/AAC.00615-09.

[17] G. Sandborgh-Englund, M. Adolfsson-Erici, G. Odham, J. Ekstrand, Pharmacokinetics of triclosan following oral ingestion in humans, J. Toxicol. Environ. Heal. Part A 69 (2006) 1861-1873, http://dx.doi.org/10.1080/ 15287390600631706.

[18] A.M. Calafat, X. Ye, L.-Y. Wong, J.A. Reidy, L.L. Needham, Urinary concentrations of triclosan in the U.S. population: 2003-2004, Environ. Health Perspect. 116 (2007) 303-307, http://dx.doi.org/10.1289/ehp.10768. 
[19] M. Adolfsson-Erici, M. Pettersson, J. Parkkonen, J. Sturve, Triclosan, a commonly used bactericide found in human milk and in the aquatic environment in Sweden, Chemosphere 46 (2002) 1485-1489, http://dx.doi. org/10.1016/S0045-6535(01)00255-7.

[20] B.F.G. Pycke, L.A. Geer, M. Dalloul, O. Abulafia, A.M. Jenck, R.U. Halden, Human fetal exposure to triclosan and triclocarban in an urban population from brooklyn, New York, Environ. Sci. Technol. 48 (2014) 8831-8838, http://dx. doi.org/10.1021/es501100w.

[21] Z. Lan, T. Hyung Kim, K. Shun Bi, X. Hui Chen, H. Sik Kim, Triclosan exhibits a tendency to accumulate in the epididymis and shows sperm toxicity in male Sprague-Dawley rats, Environ. Toxicol. 30 (2015) 83-91, http://dx.doi.org/10. 1002/tox.21897.

[22] L.M. Zorrilla, E.K. Gibson, S.C. Jeffay, K.M. Crofton, W.R. Setzer, R.L. Cooper, T.E. Stoker, The effects of triclosan on puberty and thyroid hormones in male wistar rats, Toxicol. Sci. 107 (2009) 56-64, http://dx.doi.org/10.1093/toxsci/ kfn225.

[23] V. Kumar, A. Chakraborty, M.R. Kural, P. Roy, Alteration of testicular steroidogenesis and histopathology of reproductive system in male rats treated with triclosan, Reprod. Toxicol. 27 (2009) 177-185, http://dx.doi.org/ 10.1016/j.reprotox.2008.12.002.

[24] V. Kumar, C. Balomajumder, P. Roy, Disruption of LH-induced testosterone biosynthesis in testicular Leydig cells by triclosan: probable mechanism of action, Toxicology 250 (2008) 124-131, http://dx.doi.org/10.1016/j.tox.2008. 06.012.

[25] J. Chen, K.C. Ahn, N.A. Gee, S.J. Gee, B.D. Hammock, B.L. Lasley, Antiandrogenic properties of parabens and other phenolic containing small molecules in personal care products, Toxicol. Appl. Pharmacol. 221 (2007) 278-284, http:// dx.doi.org/10.1016/j.taap.2007.03.015.

[26] R.H. Gee, A. Charles, N. Taylor, P.D. Darbre, Oestrogenic and androgenic activity of triclosan in breast cancer cells, J. Appl. Toxicol. 28 (2008) 78-91, http://dx.doi.org/10.1002/jat.1316.

[27] U.S. Environmental Protection Agency, Endocrine Disruptor Screening Program Test Guidelines OCSPP 890.1400, Hershberger Assay, Washington, 2011.

[28] OECD/OCDE, Test No. 416: Two-Generation Reproduction Toxicity, OECD Publishing, 2001, 2017, http://dx.doi.org/10.1787/9789264070868-en.

[29] U.S. Environmental Protection Agency, Reregistration Eligibility Decision for Triclosan: List B. EPA 739/RO/8009, US Environmental Protection Agency, Washington, 2008.

[30] G.A. Umbuzeiro, Guia De Potabilidade Para Substâncias Químicas, Associação Brasileira de Engenharia Sanitária e Ambiental, São Paulo, 2012.

[31] WHO, Guidelines for Drinking-Water Quality, 4th ed., World Health Organization, 2011

[32] U.S. Environmental Protection Agency, Harmonization in Interspecies Extrapolation: Use of BW 3/4 as Default Method in Derivation of the Oral RfD, 2006.

[33] D.M. Rotroff, B.A. Wetmore, D.J. Dix, S.S. Ferguson, H.J. Clewell, K.A. Houck, E.L. LeCluyse, M.E. Andersen, R.S. Judson, C.M. Smith, M.A. Sochaski, R.J. Kavlock, F. Boellmann, M.T. Martin, D.M. Reif, J.F. Wambaugh, R.S. Thomas, Incorporating human dosimetry and exposure into high-throughput in vitro toxicity screening, Toxicol. Sci. 117 (2010) 348-358, http://dx.doi.org/10.1093/toxsci/ kfq220.

[34] D. Gerardin, M. Bernardi, E. Moreira, O. Pereira, Neuroendocrine and reproductive aspects of adult male rats exposed neonatally to an antiestrogen, Pharmacol. Biochem. Behav. 83 (2006) 618-623, http://dx.doi. org/10.1016/j.pbb.2006.03.026.

[35] A. Ågmo, Male rat sexual behavior, Brain Res. Protoc. 1 (1997) 203-209, http://dx.doi.org/10.1016/S1385-299X(96)00036-0.

[36] A. Ågmo, Lack of opioid or dopaminergic effects on unconditioned sexual incentive motivation in male rats, Behav. Neurosci. 117 (2003) 55-68, http:/ dx.doi.org/10.1037/0735-7044.117.1.55.

[37] J.E. Perobelli, M.F. Martinez, C.A. da Silva Franchi, C.D.B. Fernandez, J.L.V. de Camargo, W.D.G. Kempinas, Decreased sperm motility in rats orally exposed to single or mixed pesticides, J. Toxicol. Environ. Heal. Part A 73 (2010) 991-1002, http://dx.doi.org/10.1080/15287391003751802.

[38] A.P.A. Favareto, C.D.B. Fernandez, D.A.F. da Silva, J.A. Anselmo-Franci, W.D.G. Kempinas, Persistent impairment of testicular histology and sperm motility in adult rats treated with cisplatin at peri-puberty, Basic Clin. Pharmacol. Toxicol. 109 (2011) 85-96, http://dx.doi.org/10.1111/j.1742-7843.2011. 00688.x.

[39] L. Björndahl, I. Söderlund, U. Kvist, Evaluation of the one-step eosin-nigrosin staining technique for human sperm vitality assessment, Hum. Reprod. 18 (2003) 813-816, http://dx.doi.org/10.1093/humrep/deg199.
[40] R.C. Piffer, P.C. Garcia, D.C.C. Gerardin, W.G. Kempinas, O.C.M. Pereira, Semen parameters, fertility and testosterone levels in male rats exposed prenatally to betamethasone, Reprod. Fertil. Dev. 21 (2009) 634, http://dx.doi.org/10. 1071/RD08203.

[41] G.S.A. Fernandes, A.C. Arena, C.D.B. Fernandez, A. Mercadante, L.F. Barbisan, W.G. Kempinas, Reproductive effects in male rats exposed to diuron, Reprod. Toxicol. 23 (2007) 106-112, http://dx.doi.org/10.1016/j.reprotox.2006.09.002.

[42] J. Seed, R.E. Chapin, E.D. Clegg, L.A. Dostal, R.H. Foote, M.E. Hurtt, G.R. Klinefelter, S.L. Makris, S.D. Perreault, S. Schrader, D. Seyler, R. Sprando, K.A. Treinen, D.N.R. Veeramachaneni, L.D. Wise, Methods for assessing sperm motility, morphology, and counts in the rat, rabbit, and dog: a consensus report, Reprod. Toxicol. 10 (1996) 237-244, http://dx.doi.org/10.1016/08906238(96)00028-7.

[43] R. Filler, Methods for evaluation of rat epididymal sperm morphology, in: Male Reprod. Toxicol, Elsevier, 1993, 2017, pp. 334-343, http://dx.doi.org/10. 1016/B978-0-12-461207-5.50025-0.

[44] G.W. Robb, R.P. Amann, G.J. Killian, Daily sperm production and epididymal sperm reserves of pubertal and adult rats, Reproduction 54 (1978) 103-107, http://dx.doi.org/10.1530/jrf.0.0540103.

[45] L.R. França, C.L. Godinho, Testis morphometry, seminiferous epithelium cycle length, and daily sperm production in domestic cats (Felis catus), Biol. Reprod. 68 (2003) 1554-1561, http://dx.doi.org/10.1095/biolreprod.102.010652.

[46] J. Attal, M. Courot, C. Richetin, C. Pisselet, Développement Testiculaire Et Établissement De La Spermatogenèse Chez Le Taureau, Ann. Biol. Anim. Biochim. Biophys. 3 (1963) 219-241, http://dx.doi.org/10.1051/ rnd:19630302.

[47] V.J. Dorst, H. Sajonski, Morphometrische untersuchunhen am tubulussystem des schweinehodens während der postnatalen entwicklug, Monatshafte Für Vet. Medizine 29 (1974) 650-652.

[48] OECD/OCDE, 441: Hershberger Bioassay in Rats, OECD Publishing, 2009, http://dx.doi.org/10.1787/9789264076334-en.

[49] H.N. Bhargava, P.A. Leonard, Triclosan: applications and safety, Am. J. Infect. Control. 24 (1996) 209-218.

[50] K. Kolšek, M. Gobec, I. Mlinarič Raščan, M. Sollner Dolenc, Screening of bisphenol A, triclosan and paraben analogues as modulators of the glucocorticoid and androgen receptor activities, Toxicol. Vitr. 29 (2015) 8-15 http://dx.doi.org/10.1016/j.tiv.2014.08.009.

[51] E. Mihaich, M. Capdevielle, D. Urbach-Ross, B. Slezak, Hypothesis-driven weight-of-evidence analysis of endocrine disruption potential: a case study with triclosan, Crit. Rev. Toxicol. 47 (2017) 263-285, http://dx.doi.org/10. 1080/10408444.2016.1269722.

[52] N.S. Canteras, Hypothalamic goal-directed behavior - ingestive, reproductive and defensive, in: Mouse Nerv. Syst., Elsevier, 2012, 2017, pp. 539-562, http://dx.doi.org/10.1016/B978-0-12-369497-3.10020-2.

[53] E.M. Hull, J.M. Dominguez, Getting his act together: roles of glutamate, nitric oxide, and dopamine in the medial preoptic area, Brain Res. 1126 (2006) 66-75, http://dx.doi.org/10.1016/j.brainres.2006.08.031.

[54] A.M. Johnson, Analysis of animal weight gains in chronic toxicity studies, J. Toxicol. Environ. Health. 7 (1981) 307-316, http://dx.doi.org/10.1080/ 15287398109529981.

[55] R.S. Sellers, D. Mortan, B. Michael, N. Roome, J.K. Johnson, B.L. Yano, R. Perry, K. Schafer, Society of toxicologic pathology position paper: organ weight recommendations for toxicology studies, Toxicol. Pathol. 35 (2007) 751-755, http://dx.doi.org/10.1080/01926230701595300.

[56] W.W. Ku, R.E. Chapin, R.N. Wine, B.C. Gladen, Testicular toxicity of boric acid (BA): relationship of dose to lesion development and recovery in the F344 rat, Reprod. Toxicol. 7 (1993) 305-319, http://dx.doi.org/10.1016/08906238(93)90020-8.

[57] R. Poon, Short-term oral toxicity of pentyl ether, 1,4-diethoxybutane, and 1,6-dimethoxyhexane in male rats, Toxicol. Sci. 77 (2003) 142-150, http://dx. doi.org/10.1093/toxsc/kfg251.

[58] T. Pakarainen, F.-P. Zhang, S. Mäkelä, M. Poutanen, I. Huhtaniemi, Testosterone replacement therapy induces spermatogenesis and partially restores fertility in luteinizing hormone receptor knockout mice, Endocrinology 146 (2005) 596-606, http://dx.doi.org/10.1210/en.2004-0913.

[59] L.R. de Franca, L.D. Russell, The testis of domestic mammals, in: F. Martínez-Garcia, J. Regadera (Eds.), Male Reprod. A Multidiscip. Overv., Churchill comunications, Madrid, 1998, pp. 198-219. 